\title{
NDC ML (Milliliter)
}

National Cancer Institute

\section{Source}

National Cancer Institute. NDC ML (Milliliter). NCI Thesaurus. Code C155840.

A recognized billing qualifier that may be used to identify a milliliter as the NDC unit of measure. This is often used when describing a liquid, solution, or suspension. 